\title{
Correlation of Initial Computed Tomography Findings with Outcomes of Patients with Acute Subdural Hematoma: A Prospective Study
}

\author{
Ajay Choudhary ${ }^{1}$ Kaviraj Kaushik ${ }^{1}$ Surya Narayanan Bhaskar ${ }^{1} \quad$ Laxmi Narayan Gupta $^{1}$ \\ Rajesh Sharma ${ }^{1}$ Rahul Varshney ${ }^{1}$ \\ 1Department of Neurosurgery, Atal Bihari Vajpayee Institute of \\ Medical Sciences, Ram Manohar Lohia Hospital, New Delhi, India

\begin{abstract}
Address for correspondence Kaviraj Kaushik, MCh, Department of Neurosurgery, Atal Bihari Vajpayee Institute of Medical Sciences, Ram Manohar Lohia Hospital, Baba Kharak Singh Road, Near Gurudwara Bangla Sahib, Connaught Place, New Delhi 110001, India (e-mail: kabirapgims@gmail.com).
\end{abstract}

Indian J Neurotrauma:2021;18:19-25

\begin{abstract}
Introduction In modern emergency service systems, patients are often treated with sedation, intubation, and ventilation at the accident site. But neurosurgical assessment before all these emergency services is important. Thus, this study was designed to investigate the relationships between various parameters of initial CT scan findings and the outcomes of the patients.

Methodology A total of 56 adult patients of traumatic acute subdural hematoma (SDH) whose computed tomography (CT) scan was performed within 8 hours of injury were recruited. The patients with prolonged hypotension, open head injury or depressed skull fracture, bilateral side acute SDH, or contusions/hematoma/extradural hematoma on the contralateral side were excluded. Six separate $C T$ findings were analyzed and recorded, including hematoma, midline shift, subarachnoid hemorrhage $(\mathrm{SAH})$, presence of basal cistern obliteration (BCO), intraparenchymal hematoma/ contusion in the same hemisphere, and presence of effacement of the sulcal spaces, and were followed up for three months for outcome analysis.

Results The overall mortality and functional recovery rate were 27 and $50 \%$, respectively. The patients with obliterated basal cisterns and the presence of underlying SAH in patients with acute SDH had statistically significant poorer outcomes as compared

Keywords

- traumatic brain injury

- subarachnoid hemorrhage

$-\mathrm{SDH}$

- CT findings

- basal cistern obliteration with others. However, the extent of midline shift, SDH thickness, and the presence of underlying contusions and sulcal effacement on initial CT scan showed no statistically significant correlation with patients' outcomes.

Conclusions BCO and presence of subarchnoid hemorrhage underlying acute SDH on the earliest scan in head injury patients signify the severity of brain parenchymal injury. Along with the initial Glasgow Coma Scale score after resuscitation, these two factors should be considered as the most significant ones for predicting the outcomes in traumatic acute SDH patients.
\end{abstract}

published online

September 9, 2020
DOI https://doi.org/

$10.1055 / \mathrm{s}-0040-1713721$

ISSN 0973-0508.
(C2020. Neurotrauma Society of India.

This is an open access article published by Thieme under the terms of the Creative Commons Attribution-NonDerivative-NonCommercial-License, permitting copying and reproduction so long as the original work is given appropriate credit. Contents may not be used for commercial purposes, or adapted, remixed, transformed or built upon. (https://creativecommons.org/licenses/by-nc-nd/4.0/).

Thieme Medical and Scientific Publishers Pvt. Ltd. A-12, 2nd Floor, Sector 2, Noida-201301 UP, India 


\section{Introduction}

In view of the growing population and increased vehicle use, traumatic brain injury (TBI) is becoming the most common and devastating problem, especially in young healthy people. Trauma is one of the most common cause of death and lifelong disability in the early decades of life, of which majority of cases are neurological trauma. ${ }^{1}$ The total volume of TBI in India is unknown, but estimates suggest that there are more than a million trauma-related deaths in India per year, of which $50 \%$ are related to $\mathrm{TBI}{ }^{2}$ The mortality is high in cases of traumatic acute subdural hematoma (ASDH), with reported rates ranging from 50 to $90 \% .^{3-6}$ Several factors that influence the outcomes in these cases have been studied extensively, including patient age, initial Glasgow Coma Scale (GCS) score, timing of surgical intervention, and initial computed tomography (CT) findings. ${ }^{3-10}$

In modern emergency service systems, patients are often treated with sedation, intubation, and ventilation at the accident site before a neurosurgical assessment is performed. These treatments make it impossible to assess neurological status accurately on arrival at the hospital. In such cases, surgical decisions and prognosis prediction are largely based on initial CT findings. ${ }^{8,9}$

\section{Methodology}

A total of 56 adult patients of traumatic acute SDH, whose CT scan was performed within 8 hours of injury were recruited. The patients with prolonged hypotension due to other major systemic injury, those with open head injury or depressed skull fracture, and those with bilateral side acute SDH or contusions/hematoma/extradural hematoma on the contralateral side were excluded. The severity of head injury was based on the GCS score system. Patients were treated as per the management plan based on clinical and radiological findings. The following six separate CT findings were analyzed and recorded:

- Subdural hematoma thickness.

- Extent of midline shift.

- Presence of subarachnoid hemorrhage (SAH).

- Presence of basal cistern obliteration (BCO).

- Presence of intraparenchymal hematoma/contusion (IPH/C) in the same hemisphere.

- Presence of effacement of the sulcal spaces.

Patients were followed up for a minimum of 3 months, and their outcomes were assessed using the Glasgow Outcome Scale (GOS). GOS I, II, \& III were accepted as poor outcomes and GOS IV and V as good outcomes. Mortality rates were calculated in relation to the parameters listed previously.

Statistical analysis was performed using chi-square and Fisher's exact tests. A $p$-value of $<0.05$ was considered to indicate a statistically significant difference.

\section{Results}

A total of 56 patients were enrolled in the study. The mortality and survival rates were $27 \%$ (15/56 patients died) and $73 \%$ (41/56 patients achieved functional recovery), respectively.
The results analysis was performed on the basis of the following parameters:

- Severity of head injury (-Table $\mathbf{1}$ ).

- CT scan findings (- Table 2):

- SDH thickness.

- Extent midline shift.

- SAH.

- BCO.

- IPH/C in the same hemisphere.

- Effacement of the sulcal spaces.

Table 1 Patient outcome correlation with GCS score on presentation

\begin{tabular}{|l|l|l|l|}
\hline $\begin{array}{l}\text { GCS on } \\
\text { presentation }\end{array}$ & $\begin{array}{l}\text { Poor } \\
\text { outcome }\end{array}$ & $\begin{array}{l}\text { Good } \\
\text { outcome }\end{array}$ & -Value \\
\hline $\begin{array}{l}\text { Severe head injury } \\
(n=31)\end{array}$ & 24 & 7 & $<0.0001$ \\
\cline { 1 - 2 } $\begin{array}{l}\text { Moderate head injury } \\
(n=17)\end{array}$ & 9 & 8 & \\
\cline { 1 - 2 } $\begin{array}{l}\text { Mild head injury } \\
(n=8)\end{array}$ & 0 & 8 & \\
\hline
\end{tabular}

Abbreviation: GCS, Glasgow Coma Scale.

Table 2 Patient outcome correlation with various CT parameters

\begin{tabular}{|c|c|c|c|}
\hline SDH thickness & $\begin{array}{l}\text { Poor } \\
\text { outcome }\end{array}$ & $\begin{array}{l}\text { Good } \\
\text { outcome }\end{array}$ & $p$-Value \\
\hline$<5 \mathrm{~mm}(n=17)$ & 13 & 4 & \multirow[t]{3}{*}{0.26} \\
\hline $5-10 \mathrm{~mm}(n=27)$ & 14 & 13 & \\
\hline$>10 \mathrm{~mm}(n=12)$ & 7 & 5 & \\
\hline Midline shift & $\begin{array}{l}\text { Poor } \\
\text { outcome }\end{array}$ & $\begin{array}{l}\text { Good } \\
\text { outcome }\end{array}$ & \multirow[t]{4}{*}{0.077} \\
\hline$<5 \mathrm{~mm}(n=15)$ & 7 & 8 & \\
\hline $5-10 \mathrm{~mm}(n=35)$ & 21 & 14 & \\
\hline$>10 \mathrm{~mm}(n=6)$ & 6 & 0 & \\
\hline Basal cisterns & $\begin{array}{l}\text { Poor } \\
\text { outcome }\end{array}$ & $\begin{array}{l}\text { Good } \\
\text { outcome }\end{array}$ & \multirow[t]{3}{*}{0.001} \\
\hline Obliterated $(n=28)$ & 23 & 5 & \\
\hline Patent $(n=28)$ & 11 & 17 & \\
\hline Underlying contusion & $\begin{array}{l}\text { Poor } \\
\text { outcome }\end{array}$ & $\begin{array}{l}\text { Good } \\
\text { outcome }\end{array}$ & \multirow[t]{3}{*}{0.299} \\
\hline Present $(n=16)$ & 8 & 8 & \\
\hline Absent $(n=40)$ & 26 & 14 & \\
\hline Underlying SAH & $\begin{array}{l}\text { Poor } \\
\text { outcome }\end{array}$ & $\begin{array}{l}\text { Good } \\
\text { outcome }\end{array}$ & \multirow[t]{3}{*}{0.001} \\
\hline No SAH $(n=23)$ & 8 & 15 & \\
\hline SAH present $(n=33)$ & 26 & 7 & \\
\hline Sulcal effacement & $\begin{array}{l}\text { Poor } \\
\text { outcome }\end{array}$ & $\begin{array}{l}\text { Good } \\
\text { outcome }\end{array}$ & \multirow[t]{3}{*}{0.067} \\
\hline No sulcus effaced $(n=8)$ & 2 & 6 & \\
\hline $\begin{array}{l}\text { Sulcal effacement } \\
\text { present }(n=48)\end{array}$ & 31 & 17 & \\
\hline
\end{tabular}

Abbreviations: $\mathrm{CT}$, computed tomography; $\mathrm{SAH}$, subarachnoid hemorrhage; $\mathrm{SDH}$, subdural hematoma. 


\section{Severity of Head Injury}

There were $31(51.35 \%)$ patients with severe head injury (GCS score: $3-8$ ), 17 patients with moderate head injury (GCS score: 9-12), and 8 with mild head injury (GCS score: $13-15$ ).

In the severe head injury group, 24 (77.5\%) patients had poor outcomes and 7 patients(22.5\%) had good outcomes. In moderate head injury group $(n=17), 8(47 \%)$ patients had good outcomess and 9 (53\%) patients had poor outcomes. In the mild head injury, all patients had good outcomes.

\section{Subdural Hematoma Thickness}

The SDH thickness was divided into the following three groups:

- $<5 \mathrm{~mm}$.

- 5-10 mm.

- $>10 \mathrm{~mm}$.

In our study, the hematoma thickness was not significantly correlated with either the initial GCS score of patients or the outcomes of patients.

\section{Midline Shift}

The midline shift was present in 49 (87.5\%) of 56 cases. In $15(26.78 \%)$ patients, the midline shift was less than $5 \mathrm{~mm}$. In our study, the extent of midline shift on the first CT scan was not found to be significantly correlated with poor outcomes.

\section{Basal Cistern Obliteration}

Basal cisterns were obliterated in the initial scan of 28 (50\%) patients and were patent in rest of the 28 (50\%) patients. The good outcomes were significantly correlated with patent basal cisterns on the initial CT scan (-Fig. 1).

\section{Underlying Contusions}

Underlying contusions were present in 40 (71.4\%) patients out of total 56, whereas in 16 patients the contusion or intraparenchymal hematoma was not visible on the first CT scan. On comparing both these groups, there was no significant correlation in the presence of underlying contusion and the outcomes of patients. Contusions may not be fully evident on the first scan performed early after trauma as it takes some time for the evolution of contusions. Hence, repeat scans after an interval are important rather than the first scan for watching contusions.

\section{Underlying Subarachnoid Hemorrhage}

Underlying cortical/cisternal SAH was recorded in 33 (58.9\%) patients, and the rest $23(41.1 \%)$ patients had no SAH. When it was compared with the outcomes of patients, those having SAH underlying SDH had significantly poorer outcomes than those who had no SAH (-Fig. 2).

\section{Sulcal Effacement}

Sulcal effacement on the initial CT scan was defined as loss of gray white differentiation due to the loss of the sulcal spaces and pushing of the adjacent gyri together. This was seen in $48(85.7 \%)$ out of 56 patients. There was no significant correlation in the outcomes of patients with respect to sulcal

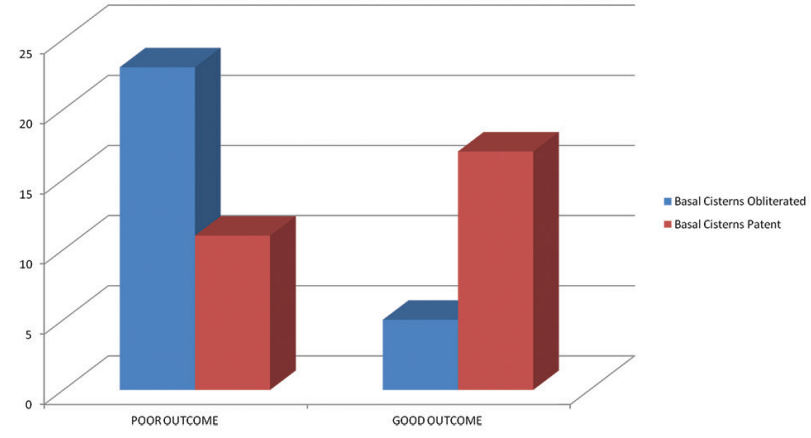

Fig. 1 Correlation between the patency of basal cisterns and the outcome of patients.

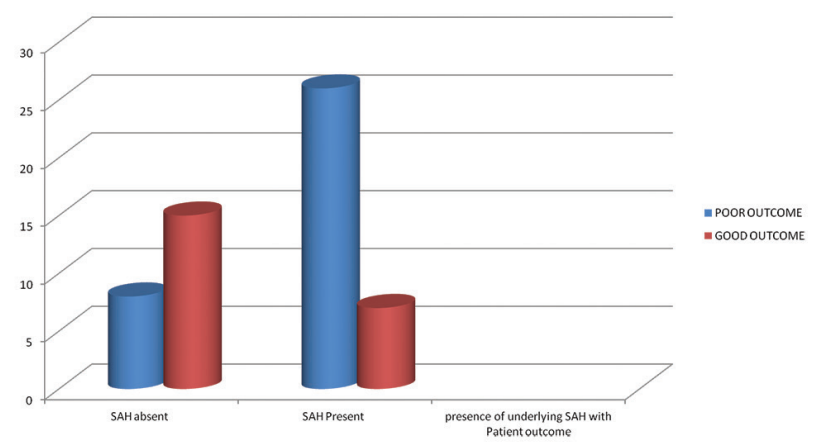

Fig. 2 Correlation between the presence of underlying subarachnoid hemorrhage and the outcome of patients.

effacement. Among 48 patients, 17 (35.5\%) had good outcomes, 10 (20.8\%) had moderate outcomes, and 31 (74.55\%) had poor outcomes. In 8 (14.3\%) patients, the sulcal effacement was not present. In these, 6 (75\%) patients had good outcomes and $2(25 \%)$ had poor outcomes.

\section{Discussion}

Many investigators have examined the relationships between initial CT findings and outcomes in patients with traumatic ASDH. ${ }^{14,5,9,11,12}$ In our study, we investigated all the commonly used CT parameters (hematoma thickness, midline shift, presence of SAH, BCO, presence of IPH/C, and sulcal effacement) in one group of patients. Our aim was to determine the value of these parameters for predicting prognosis in patients with ASDH.

On analysis of previous studies, we found no statistically significant correlation of age, sex, and mode of injury with the outcomes of patients in traumatic acute SDH. But GCS at the time of admission had a strong correlation with outcomes.

\section{Subdural Hematoma Thickness}

In our study, the hematoma thickness was not significantly correlated with either the initial GCS score of patients or the outcomes of patients (-Fig. $\mathbf{3}$ ). It is because the SDH is usually associated with underlying brain damage (e.g., cerebral contusions, hematomas, SAH, diffuse axonal injury). It is the primary brain damage that determines the outcomes of patients. SDH thickness may progressively increase with 


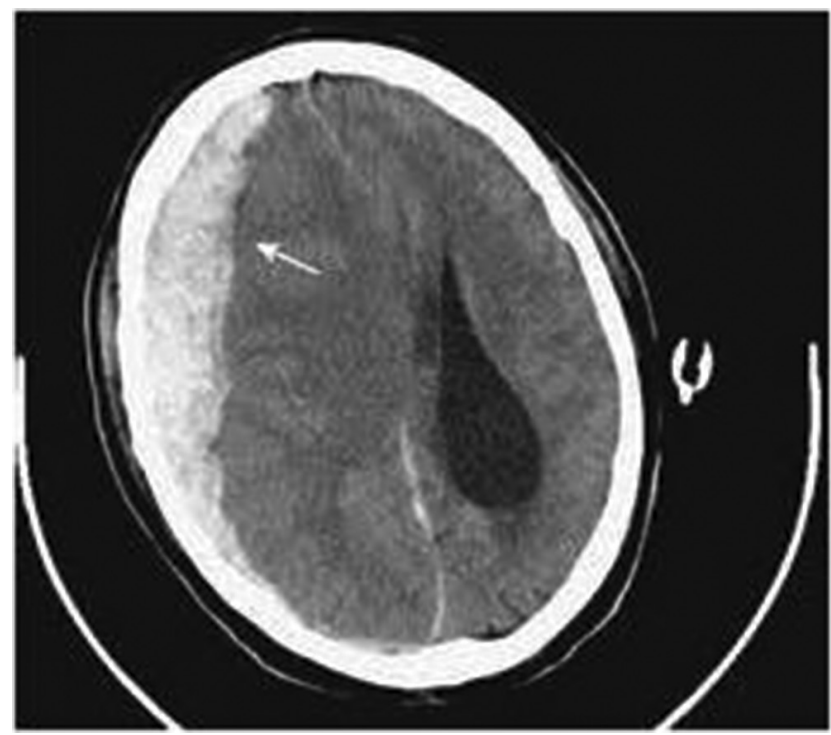

Fig. 3 Axial computed tomography showing subdural hematoma thickness.

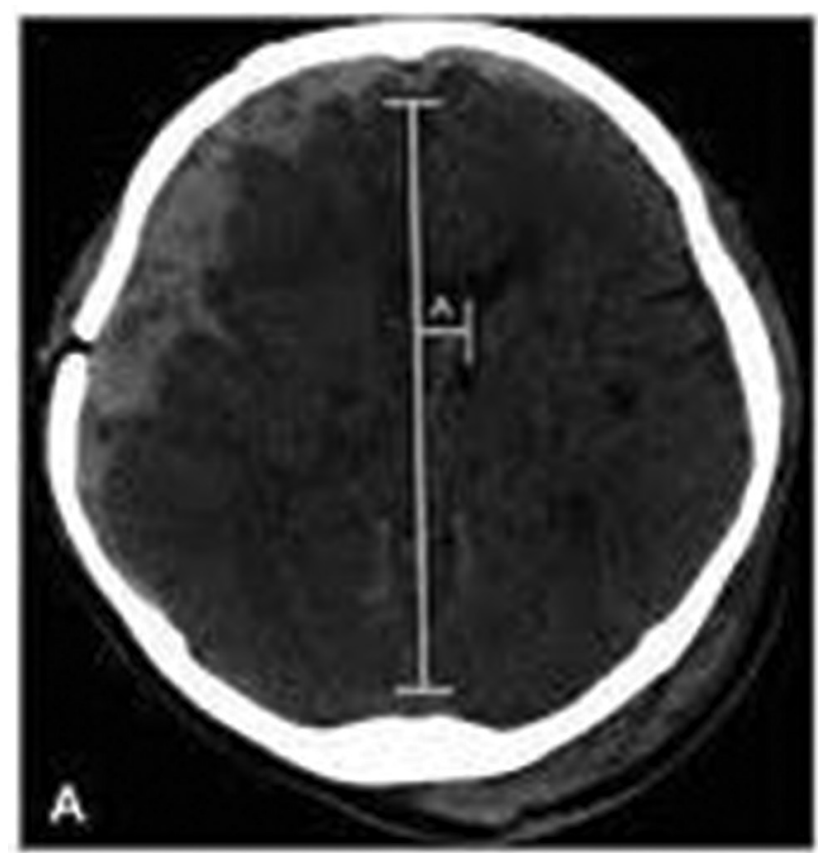

Fig. 4 Measuring the extent of the midline shift on axial computed tomography.

time, which may not be evident on the initial CT scan. This finding is also supported by various previous studies. ${ }^{10,12,13}$

\section{Midline Shift}

Numerous reports describe the association of a large amount of midline shift on CT scan (usually described as $>5 \mathrm{~mm}$ ) with poor outcomes or other adverse sequelae of TBI ( - Fig. 4). Our study also shows that patients may tolerate midline shift of up to $1 \mathrm{~cm}$ better than more than $1 \mathrm{~cm}$, as all patients with midline shift more than $1 \mathrm{~cm}$ had a poor GCS score on presentation, and also none of these patients had good outcomes at three-month follow-up.

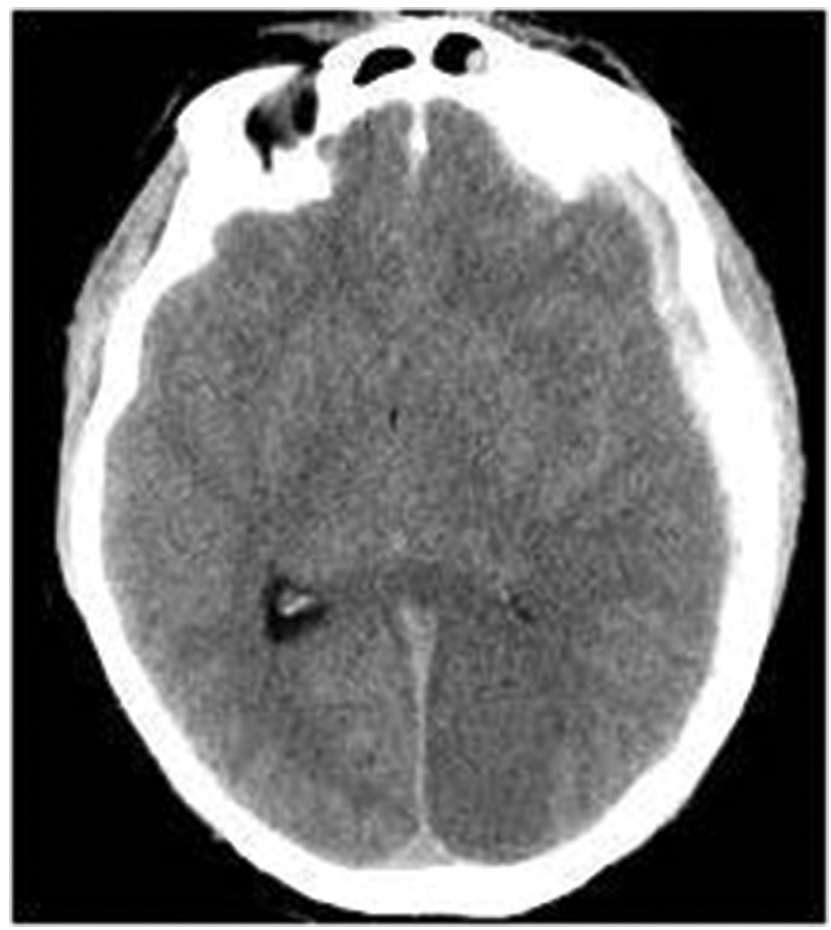

Fig. 5 Axial computed tomography showing obliterated basal cisterns with acute subdural hematoma.

\section{Basal Cistern Obliteration}

Compression of basal cisterns closely correlated with an intracranial pressure (ICP) greater than $20 \mathrm{~mm} \mathrm{Hg}$, with clinical signs of midbrain dysfunctions and worse prognosis (-Fig. 5)..$^{14}$ In modern CT scanning, no matter how young the patient, it should always be possible to identify the third ventricle and basal cisterns; in normal situation, the ambient cistern is smallest and most easily compressed followed by the quadrigeminal cistern. When ICP rises either due to hematoma (SDH/contusion) or due to parenchymal edema, there is a downward shift of the brain, leading to obliteration of basal cisterns. Hence BCO is an indicator of raised ICP and impending downward herniation of the brain. In elderly patients, the brain is atrophic, and these patients tolerate more midline shift or hematoma thickness as compared with young, but when they show obliteration of basal cisterns, it is surely a predictor of significantly raised ICP and the brain herniates. Similarly, in cases of bilateral side head injury, the midline shift may not contribute to the clinical status, but $\mathrm{BCO}$ will be a more reliable predictor of outcomes. On statistical analysis, comparing the outcomes of patients with effaced cisterns was significantly poorer as compared with patients with patent basal cisterns ( $p=0.001$ and $<00.05$, respectively), which is also in accordance with literature and previous studies

\section{Underlying Contusions/Hematoma}

Brain contusion in patients with traumatic ASDH leads to decreased cerebral blood flow, increased ischemic damage, and rapid development of brain swelling ( Furthermore, intraparenchymal hematomas may result in increased ICP and midline shift. These intracranial space-occupying lesions should be considered poor prognostic 


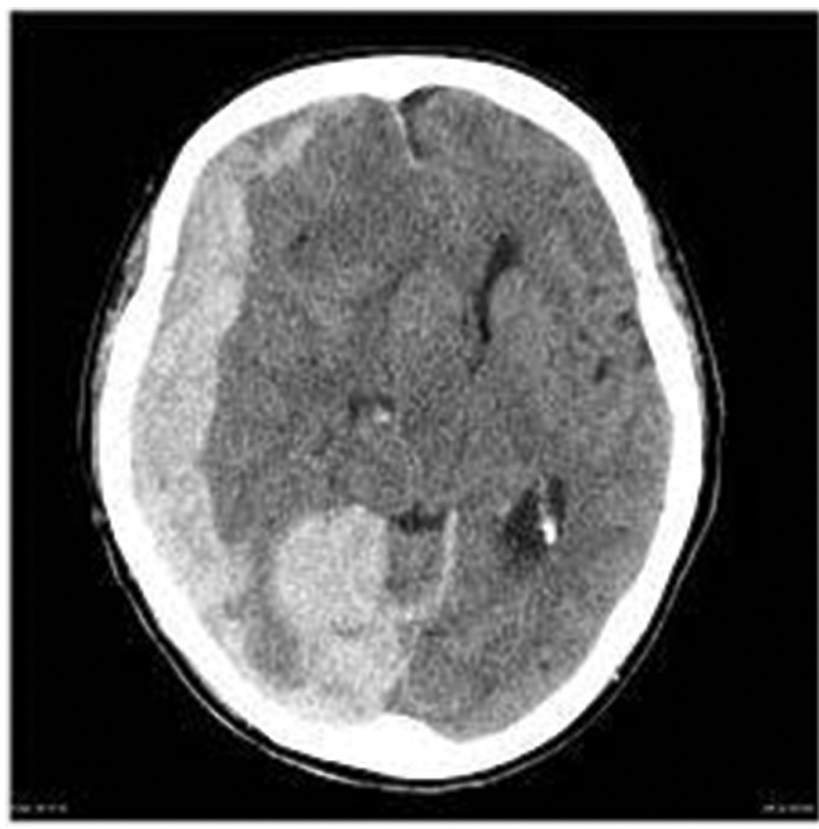

Fig. 6 Large underlying ipsilateral occipital hematoma with acute subdural hematoma.

factors. Servadei et al in their study of 206 acute SDH patients concluded that early CT underestimates the ultimate size of parenchymal contusions and may not be reliable for secondary brain damage due to associated underlying contusions. ${ }^{18}$ Various authors have reported an incidence of progression of intracranial lesions or appearance of a new lesion on repeat CT scan ranging from less than $10 \%$ to as high as $68 \%^{19-29}$ Progressive hemorrhagic injury was reported overall in $42.3 \%$ and in $87 \%$ of patients who underwent their first CT within 2 hours of injury.

In this study, there was no significant correlation between the presence of underlying contusion and the outcomes of patients.

\section{Underlying Subarachnoid Hemorrhage}

Traumatic SAH has cisternal (basal cisterns, interhemispheric spaces, and Sylvian fissures) or sulcal (cortical convexity) distributions and results from a relatively severe injury to the brain (-Fig. 7). High angular acceleration of considerable duration is necessary to produce sufficient strain to rupture superficial vessels in the subarachnoid spaces. Posttraumatic vasospasm can also occur early (within 5 days) and induce focal or diffuse cerebral edema. ${ }^{13}$

Accordingly, the presence of combined contusion or SAH with ASDH indicates ASDH associated with substantial impact and more severe brain parenchymal injury, which can worsen the course of the ASDH during the acute phase by the aforementioned mechanisms. Patients with traumatic SAH have a significantly worse outcomes than those without SAH. Son et al concluded that the presence of SAH with ASDH was found to be significantly related, and correlated with the severity of initial injury as estimated by initial GCS scores. ${ }^{13}$

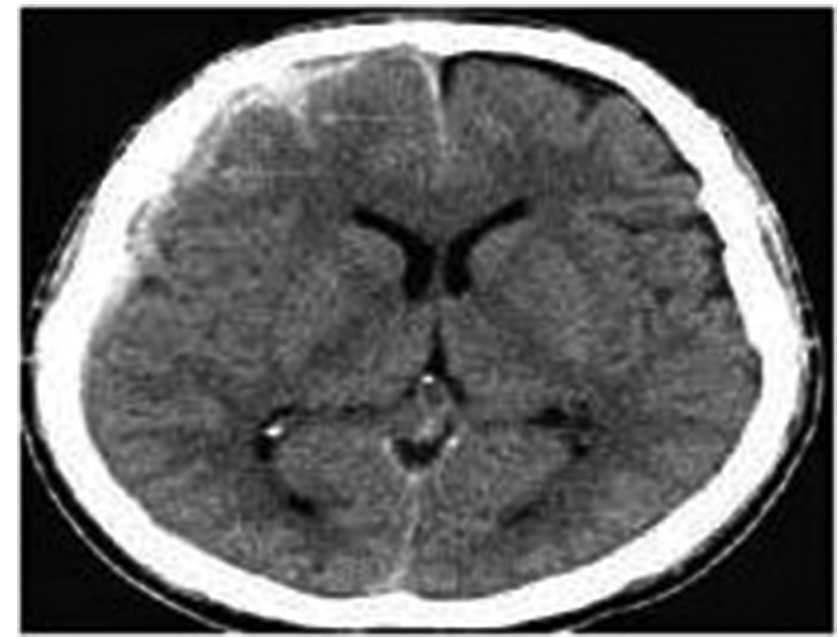

Fig. 7 Underlying cortical subarachnoid hemorrhage in patients with acute subdural hematoma.

Servadei et al. in their study of prognostic value of worst CT scan in acute SDH patients found evidence of SAH on the first CT examination, which was a powerful predictor of poor outcomes (odds ratio: $0.37 ; p<0.004$ ). SDH tends to develop secondary parenchymal damage, which is underestimated by the first $\mathrm{CT} .{ }^{18} \mathrm{CT}$ signs of associated $\mathrm{SAH}$ on admission identify a population with the highest risk of developing parenchymal damage.

Harders et al reviewed the data from 683 patients in the HIT II nimodipine study and found that among those with $\mathrm{SAH}$, contusions were seen in $13 \%$ more patients on the second $\mathrm{CT}$ than on the first one. This finding confirms our data showing that SAH can be an early sign of cortical contusion even when parenchymal damage is not yet evident on the first $\mathrm{CT}^{30}$

In their study of patients with traumatic ASDH, Domenicucci et al. identified intact subarachnoid space as a favorable prognostic factor. They suggested that the integral visceral membrane of the hematoma prevents diffusion of neurotoxic and vasoactive substances into the subarachnoid space. $^{7}$

Solaroglu et al reported no statistically significant difference in outcomes between patients with intact subarachnoid space and those who had hemorrhage in the subarachnoid space. But they did note a trend toward poorer prognosis in patients with SAH. ${ }^{31}$

In our study, underlying cortical/cisternal SAH was recorded in 33 (58.9\%) patients, and the rest 23 (41.1\%) patients had no SAH. When it was compared with the outcomes of patients, those having SAH underlying SDH had significantly poorer outcomes than those who had no SAH. Out of 33 patients of SAH underlying SDH, 20 patients (60.61\%) had poor outcomes, 6 (18.18\%) had moderate outcomes, and 7 (21.21\%) had poor outcomes. In 23 patients who had no underlying SAH, 16 (69.5\%) had good outcomes, 4 (17.4\%) had moderate outcomes, and $3(13 \%)$ had poor outcomes. The presence of SAH along with ASDH was statistically significant $(p=0.001)$. 


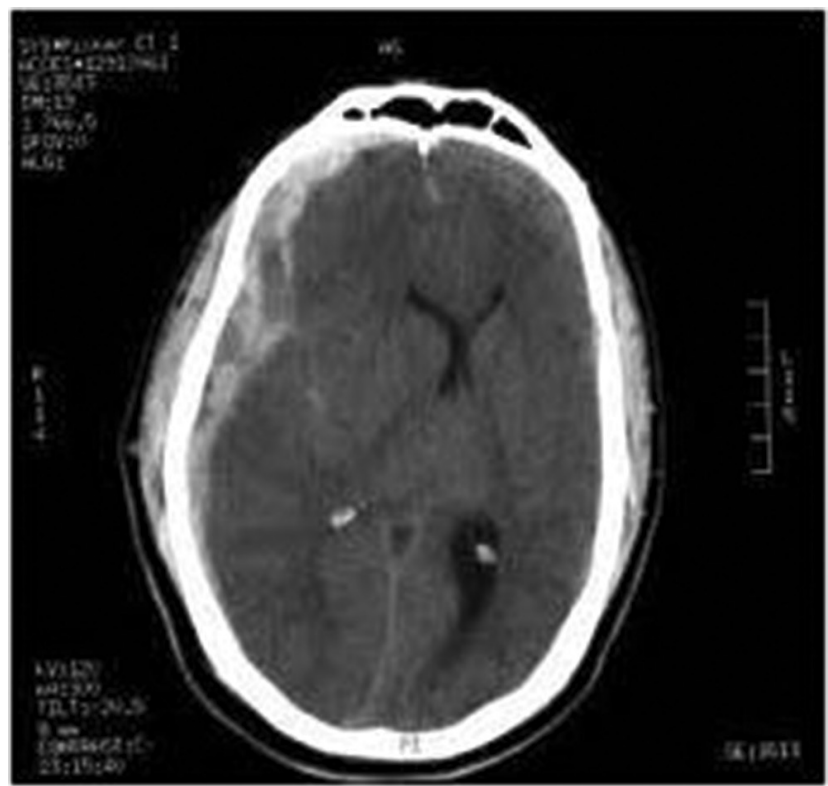

Fig. 8 Effaced sulci in patients with acute subdural hematoma.

\section{Sulcal Effacement}

Sulcal effacement is a local secondary sign of mass effect in the cranium ( $\boldsymbol{- F i g . ~ 8 )}$. Any lesion exerting a mass effect on brain parenchyma can push the adjacent gyri together, thereby displacing the cerebrospinal fluid from the sulci and leading to sulcal effacement on CT scan. There are two types of cerebral edema: vasogenic, due to the disruption of the blood-brain barrier allowing accumulation of extracellular water, and cytotoxic, due to the failure of cell membrane pumps, resulting in intracellular water leakage. Of these two types of edema, cytotoxic edema may be primarily responsible for cerebral swelling, as demonstrated by the increased water content and reduced apparent diffusion coefficient values in one magnetic resonance imaging (MRI) study. ${ }^{32}$

On imaging, cerebral swelling due to hyperemia is represented as the loss of sulci (sulcal effacement), compression of the basilar cisterns, and flattening of the ventricular margins. Children are particularly susceptible to diffuse cerebral swelling following TBI, with the incidence of diffuse swelling being approximately twofold higher in children than in adults. ${ }^{32}$ Children and young adults are more prone to posttraumatic dysautoregulation, which leads to vasodilatation, hyperemia, and cerebral swelling. When swelling is severe, ICP increases and cerebral perfusion pressure falls, resulting in infarction and cerebral damage.

\section{Conclusions}

We found that the following factors had a significant influence on the outcomes of ASDH in our study:

- The presence of combined contusion or SAH with ASDH indicates that ASDH is associated with substantial impact and more severe brain parenchymal injury and is also a strong predictor of poor outcomes in head injury patients.
- BCO, which is an indirect indicator of increased ICP, is the most important factor responsible for unfavorable outcomes.

- Still the outcomes of patients mainly depend on their clinical status and initial GCS score.

- SDH thickness, midline shift, sulcal effacement, and underlying contusions in acute SDH patients may progress with time, and although these findings affect the outcomes, on the initial scan they are not strong indicators of outcome prediction.

\section{Funding \\ None.}

\section{Conflict of Interest}

None declared.

\section{References}

1 Alberico AM, Ward JD, Choi SC, Marmarou A, Young HF. Outcome after severe head injury. Relationship to mass lesions, diffuse injury, and ICP course in pediatric and adult patients. J Neurosurg 1987;67(5):648-656

2 Maas AI. Traumatic brain injury in India: a big problem in need of data. Neurol India 2017;65(2):257-258

3 Kaptanoglu E, Solaroglu I, Ucar MD, et al. Acute subdural hematomas: analysis of 73 cases. Ulus Travma Derg 2001;7(4):246-249

4 Klun B, Fettich M. Factors influencing the outcome in acute subdural haematoma. A review of 330 cases. Acta Neurochir (Wien) 1993;121:95-99

5 Kotwica Z, Brzeziński J. Acute subdural haematoma in adults: an analysis of outcome in comatose patients. Acta Neurochir (Wien) 1993;121(3-4):95-99

6 Massaro F, Lanotte M, Faccani G, Triolo C. One hundred and twenty-seven cases of acute subdural haematoma operated on. Correlation between CT scan findings and outcome. Acta Neurochir (Wien) 1996;138(2):185-191

7 Domenicucci M, Strzelecki JW, Delfini R. Acute posttraumatic subdural hematomas: "intradural" computed tomographic appearance as a favorable prognostic factor. Neurosurgery 1998;42(1):51-55

8 Eisenberg HM, Gary HE Jr, Aldrich EF, et al. Initial CT findings in 753 patients with severe head injury. A report from the NIH Traumatic Coma Data Bank. J Neurosurg 1990;73(5):688-698

9 Zimmerman RA, Bilaniuk LT, Gennarelli T, Bruce D, Dolinskas C, Uzzell B. Cranial computed tomography in diagnosis and management of acute head trauma. AJR Am J Roentgenol 1978;131(1):27-34

10 Zumkeller M, Behrmann R, Heissler HE, Dietz H. Computed tomographic criteria and survival rate for patients with acute subdural hematoma. Neurosurgery 1996;39(4):708-712, discussion 712-713

11 Phuenpathom N, Choomuang M, Ratanalert S. Outcome and outcome prediction in acute subdural hematoma. Surg Neurol 1993;40(1):22-25

12 Servadei F. Prognostic factors in severely head injured adult patients with acute subdural haematoma's. Acta Neurochir (Wien) 1997;139(4):279-285

13 Son S, Yoo CJ, Lee SG, Kim EY, Park CW, Kim WK. Natural course of initially non-operated cases of acute subdural hematoma: the risk factors of hematoma progression. J Korean Neurosurg Soc 2013;54(3):211-219 
14 Teasdale E, Cardoso E, Galbraith S, Teasdale G. CT scan in severe diffuse head injury: physiological and clinical correlations. J Neurol Neurosurg Psychiatry 1984;47(6):600-603

15 Overgaard J, Tweed WA. cerebral blood flow and its regulation after closed head injury with emphasis on clinical correclations. J Neurosurg 1974;41:531-541

16 Graham DI, Adams JH, Doyle D. Ischaemic brain damage in fatal non-missile head injuries. J Neurol Sci 1978;39(2-3): 213-234

17 Muizelaar JP, Wei EP, Kontos HA, Becker DP. Mannitol causes compensatory cerebral vasoconstriction and vasodilation in response to blood viscosity changes. J Neurosurg 1983;59(5): $822-828$

18 Servadei F, Murray GD, Teasdale GM, et al. Traumatic subarachnoid hemorrhage: demographic and clinical study of 750 patients from the European brain injury consortium survey of head injuries. Neurosurgery 2002;50(2):261-267, discussion 267-269

19 Lee TT, Aldana PR, Kirton OC, Green BA. Follow-up computerized tomography (CT) scans in moderate and severe head injuries: correlation with Glasgow Coma Scores (GCS), and complication rate. Acta Neurochir (Wien) 1997;139(11): 1042-1047, discussion 1047-1048

20 Servadei F, Nanni A, Nasi MT, et al. Evolving brain lesions in the first 12 hours after head injury: analysis of 37 comatose patients. Neurosurgery 1995;37(5):899-906, discussion 906-907

21 Figg RE, Burry TS, Vander Kolk WE. Clinical efficacy of serial computed tomographic scanning in severe closed head injury patients. J Trauma 2003;55(6):1061-1064

22 Wang MC, Linnau KF, Tirschwell DL, Hollingworth W. Utility of repeat head computed tomography after blunt head trauma: a systematic review. J Trauma 2006;61(1):226-233
23 Oertel M, Kelly DF, McArthur D, et al. Progressive hemorrhage after head trauma: predictors and consequences of the evolving injury. J Neurosurg 2002;96(1):109-116

24 Cooper PR, Maravilla K, Moody S, Clark WK. Serial computerized tomographic scanning and the prognosis of severe head injury. Neurosurgery 1979;5(5):566-569

25 Givner A, Gurney J, O'Connor D, Kassarjian A, Lamorte WW, Moulton S. Reimaging in pediatric neurotrauma: factors associated with progression of intracranial injury. J Pediatr Surg 2002;37(3):381-385

26 Kaups KL, Davis JW, Parks SN. Routinely repeated computed tomography after blunt head trauma: does it benefit patients? J Trauma 2004;56(3):475-480, discussion 480-481

27 Sakai H, Takagi H, Ohtaka H, Tanabe T, Ohwada T, Yada K. Serial changes in acute extradural hematoma size and associated changes in level of consciousness and intracranial pressure. J Neurosurg 1988;68(4):566-570

28 Soloniuk D, Pitts LH, Lovely M, Bartkowski H. Traumatic intracerebral hematomas: timing of appearance and indications for operative removal. J Trauma 1986;26(9):787-794

29 Yadav YR, Basoor A, Jain G, Nelson A. Expanding traumatic intracerebral contusion/hematoma. Neurol India 2006;54(4): 377-381

30 Harders A, Kakarieka A, Braakman R. Traumatic subarachnoid hemorrhage and its treatment with nimodipine. German tSAH Study Group. J Neurosurg 1996;85(1):82-89

31 Solaroglu I, Kaptanoglu E, Okutan O, et al. Prognostic value of initial computed tomography findings in patients with traumatic acute subdural hematoma. Turk Neurosurg 2002;12:89-94

32 Langfitt TW, Tannanbaum HM, Kassell NF. The etiology of acute brain swelling following experimental head injury. J Neurosurg 1966;24(1):47-56 